\title{
Tetramethylpyrazine alleviates acute kidney injury by inhibiting NLRP3/HIF-1 $\alpha$ and apoptosis
}

\author{
WANGNAN SUN ${ }^{1 *}$, AIQUN LI $^{2 *}$, ZHIQIANG WANG $^{1 *}$, XUHONG SUN $^{1}$, MENGHUA DONG $^{1}$, \\ FU QI $^{1}$, LIN WANG ${ }^{3}$, YUEHENG ZHANG ${ }^{1}$ and PENGCHAO DU ${ }^{1}$ \\ ${ }^{1}$ Institute of Pathology and Pathophysiology, School of Basic Medical Sciences, Binzhou Medical University; \\ ${ }^{2}$ Emergency Department, Yantai Affiliated Hospital, Binzhou Medical University, Yantai, Shandong 264003; \\ ${ }^{3}$ Department of Geriatrics, The Second Hospital of Shandong University, Jinan, Shandong 264001, P.R. China
}

Received February 1, 2020; Accepted May 20, 2020

DOI: $10.3892 / \mathrm{mmr} .2020 .11378$

\begin{abstract}
The aim of the present study was to investigate the protective effect and underlying mechanism of tetramethylpyrazine (TMP) on renal ischemia reperfusion injury (RIRI) in rats, which refers to the injury caused by the restoration of blood supply and reperfusion of the kidney after a period of ischemia. Sprague-Dawley rats were randomly divided into a Sham group, renal ischemia-reperfusion (I/R) group and TMP group. TMP hydrochloride ( $40 \mathrm{mg} / \mathrm{kg}, 6 \mathrm{~h}$ intervals) was given via intraperitoneal injection immediately after reperfusion in the TMP group, after $24 \mathrm{~h}$ the kidney tissues were taken for follow-up experiments. Pathological changes in the kidney tissues were observed by periodic acid-Schiff staining. Renal function was assessed by measuring levels of serum creatinine and blood urea nitrogen, and inflammatory cytokines tumor necrosis factor (TNF)- $\alpha$ and interleukin (IL)-6. Renal cell apoptosis was detected by TUNEL-DAPI double staining, mRNA and protein changes were analyzed by reverse transcription-quantitative PCR and western blotting. Cell viability was measured using a CCK- 8 assay. It was found that the renal tissues of the sham operation group were notably abnormal, and the renal tissues of the I/R group were damaged, while the renal tissues of the TMP group were less damaged compared with those of the I/R group. Compared with the I/R group, the serum creatinine and blood urea nitrogen levels in the TMP group were low (all $\mathrm{P}<0.05$ ), levels of inflammatory cytokines TNF- $\alpha$ and IL- 6 decreased, the apoptotic rate was low (all $\mathrm{P}<0.05$ ), and the relative expression levels of
\end{abstract}

Correspondence to: Professor Pengchao Du, Institute of Pathology and Pathophysiology, School of Basic Medical Sciences, Binzhou Medical University, 346 Guanhai Road, Yantai, Shandong 264003, P.R. China

E-mail: pengchaodu@163.com

${ }^{*}$ Contributed equally

Key words: tetramethylpyrazine, NACHT LRR and PYD domains-containing protein inflammasome, hypoxia-inducible factor $1-\alpha$, apoptosis, renal ischemia reperfusion injury nucleotide-oligomerization domain-like receptor 3 (NLRP3) protein and mRNA in renal tissues were low (all $\mathrm{P}<0.05)$. The expression levels of hypoxia-inducible factor $1-\alpha$ and NLRP3 increased after oxygen and glucose deprivation (OGD), and reduced after treatment with OGD and TMP (all $\mathrm{P}<0.05$ ). It was concluded that TMP can reduce renal injury and improve renal function in RIRI rats, and its mechanism may be related to the reduction of NLRP3 expression in renal tissues.

\section{Introduction}

Renal ischemia reperfusion injury (RIRI) refers to the injury caused by the restoration of blood supply and reperfusion of the kidney after a period of ischemia due to various causes, such as reduced blood flow to the kidney from renal artery disease, systemic hypotension or maldistribution of blood flow $(1,2)$. The pathological mechanism of RIRI is complex, which includes generation of reactive oxygen species, apoptosis, hypoxia and inflammation (3), has not been fully elucidated. At present, the innate immune pattern recognition receptor NACHT LRR and PYD domains-containing protein (NLRP3) inflammasome is a research hotspot $(4,5)$. NLRP3 is an important member of the NOD-like receptor (NLR) family. When cells are stimulated by external stimuli such as infection, NLRP3 inflammasomes are formed, which are composed of NLRP3, apoptosis-associated speck-like protein containing a caspase recruitment domain (ASC) and pro-caspase 1 . Meanwhile, NLRP3 inflammasomes activate pro-caspase 1 to form caspase 1, which further cleaves pro-interleukin (IL)-18 and pro-IL-1 $\beta$ into the important bioactive inflammatory factors IL-18 and IL-1 $\beta$; these then participate in inflammatory process in vivo $(6,7)$. A study by Mezzaroma et al (8) suggested that NLRP3 may be the initial receptor in myocardial I/R injury. Sandanger et al (9) further verified that NLRP3 is the initial receptor activated by the inflammasome, which may be an important factor in the occurrence of the ischemia-reperfusion (I/R) stage after myocardial infarction.

NLRP3 was also reported to be involved in kidney injury, including renal $\mathrm{I} / \mathrm{R}$ injury. It was demonstrated that NLRP3/E3 ubiquitin-protein ligase XIAP signaling aggravated renal fibrotic injury, and also NLRP3 inflammasome activation negatively regulated podocyte autophagy in diabetic 
nephropathy $(10,11)$. Additionally, a humanized IL-6 receptor (IL-6R) antibody could reduce the activation of NLRP3 inflammasome in diabetic nephropathy, partly via suppressing IL-17A, which could be suppressed by neutralization of IL-17C in renal I/R $(12,13)$. NLRP3 knockout could protect against ischemic acute kidney injury (14). Therefore, the present study focused on NLRP3 inflammasome.

Hypoxia serves a crucial role in the development of RIRI (15). Hypoxia inducible factor (HIF), which belongs to a transcription factor family, is involved in the response to hypoxia and is sensitive to alterations in oxygen availability. HIF-1 is associated with the acute response and is involved in the transactivation of a variety of genes in cellular life activity (16). In addition, kidney injury molecule-1 (KIM-1) is a specific marker of renal acute injury (17); therefore, KIM-1 was examined to assess the renal injury in the present study.

Tetramethylpyrazine (TMP) is a bioactive alkaloid extracted from the traditional Chinese medicine chuanxiong. TMP was originally identified to treat cardiovascular and cerebrovascular diseases (18). TMP is a calcium antagonist with various pharmacological effects. For example, TMP improves microcirculation and displays antioxidation and antifibrosis effects $(19,20)$. At present, it has been widely used in the treatment of acute and chronic renal failure, diabetic nephropathy (21) and kidney cancer (22). However, the mechanism by which TMP alleviates RIPI is still unclear.

Since the pathogenic mechanism of RIPI is related to inflammation, we hypothesized that the effect of TMP in reducing RIPI is related to its anti-inflammatory effect. In the present study, the effect of TMP on the NLRP3 inflammatory corpuscle in rat kidneys was studied using a renal I/R model.

\section{Materials and methods}

Animal groups. A total of 27 male Sprague-Dawley rats (age, 8 weeks; weight, 200-220 g) were purchased from the Animal Experiment Center of Shandong University (China). The rats were randomly divided into the following groups ( $n=9$ per group): i) Sham group; ii) kidney I/R injury group (I/R group); and iii) kidney I/R injury with TMP treatment group (I/R+TMP group). Rats were kept in a clean and well-ventilated environment at a constant room temperature of $20-25^{\circ} \mathrm{C}$, a humidity of $40-70 \%$, with free access to food and water and a 12-h circadian rhythm. TMP hydrochloride for injection was purchased from Shijiazhuang Yiling Pharmaceutical Co., Ltd. This study was approved by the Animal Ethics Committee of Binzhou Medical University (China).

Establishment of RIPI model in rats. Rats were fasted for $12 \mathrm{~h}$ before surgery, but had free access to drinking water. According to the body weights of the rats, $3 \%$ pentobarbital sodium ( $50 \mathrm{mg} / \mathrm{kg}$ body weight) was intraperitoneally injected for anesthesia. The hair was removed from the backs of the animals, and the skin was disinfected using tincture of iodine. The skin was cut $0.5 \mathrm{~cm}$ along the spine and $0.5 \mathrm{~cm}$ at the lower edge of the ribs, and the muscles were separated layer by layer. Carefully, the renal arteries of both kidneys were separated, and the bilateral renal arteries were quickly closed with artery clips. After $45 \mathrm{~min}$ of ischemia, the artery clip was released, blood flow was restored, the wound was sutured, and antibiotics and a certain amount of saline (30 $\mu \mathrm{l} / \mathrm{g}$ body weight) were given. After $24 \mathrm{~h}$ of reperfusion, the anesthetized rats were given a PBS cardiac perfusion, and kidney tissues were taken for the follow-up experiments. In the Sham group, the renal artery was isolated and no ischemic treatment was performed. All other procedures were the same. In the I/R+TMP group, TMP hydrochloride was given immediately after reperfusion (40 mg/kg, 6-h interval) by intraperitoneal injection (23). At $24 \mathrm{~h}$ after the PBS cardiac perfusion, kidney tissues were taken; some tissues were stored at $-80^{\circ} \mathrm{C}$ for protein and reverse transcription-quantitative (RT-q) PCR detection, while some tissues were fixed with $4 \%$ paraformaldehyde at $4^{\circ} \mathrm{C}$ for $24 \mathrm{~h}$, embedded in paraffin, and sliced for morphological detection.

Cell culture. Rat proximal tubule epithelial cells (NRK cells; BD Biosciences) were adjusted to $1 \times 10^{5}$ and cultured in RPMI-1640 medium (HyClone; Cytiva) containing 10\% FBS (HyClone; Cytiva), with the addition of $100 \mathrm{U} / \mathrm{ml}$ penicillin-streptomycin, and placed at $37^{\circ} \mathrm{C}$ in a $5 \% \mathrm{CO}_{2}$ incubator.

Renal function test. Before cardiac perfusion, 0.5-1 $\mathrm{ml}$ of blood was extracted from the heart, and after standing for $30 \mathrm{~min}$, the serum was separated by centrifugation at $3,000 \mathrm{xg}$ for $10 \mathrm{~min}$ at $4^{\circ} \mathrm{C}$. The blood urea nitrogen and serum creatinine were detected using urea assay kits (cat. no. C013-1-1) and creatinine assay kits (cat. no. C011-1-1), in accordance with the manufacturer's instructions (Nanjing Jiancheng Bioengineering Institute Co., Ltd.).

Periodic acid-Schiff (PAS) staining. Paraffin-embedded sections (4- $\mu \mathrm{m}$ thick) were dewaxed at $60^{\circ} \mathrm{C}$ for $2 \mathrm{~h}$, washed with xylene at room temperature and dehydrated in a descending alcohol series (100, 90, 80 and 75\%). The sections were washed three times with PBS at room temperature. Periodate $(1 \%)$ was added for oxidation for $10 \mathrm{~min}$ at room temperature. The sections were counterstained with Harris hematoxylin for 5 min after immersion in Schiff's solution for $15 \mathrm{~min}$. The slides were rinsed and ammonia was added until a blue color was achieved. All staining steps were performed at room temperature, and cells were rinsed with tap water after each step for $5 \mathrm{~min}$. The slides were further washed in distilled water, dehydrated, cleared, mounted in resin and observed using a Leica DM 6000 B light microscope (Leica Microsystems $\mathrm{GmbH}$ ).

Renal tubular injury score criteria. The renal tubules were observed under magnification x 200. The following scoring criteria were used: i) 0 , no damage; ii) $1,0-10 \%$; iii) $2,11-25 \%$; iv) $3,26-45 \%$; v) $4,46-75 \%$; vi) and $5,>75 \%$.

Detection of cytokines and KIM-1. Sample diluent (100 $\mu \mathrm{l})$ and rat serum $(100 \mu \mathrm{l})$ was added to the wells and incubated at $37^{\circ} \mathrm{C}$ for $2 \mathrm{~h}$. Subsequently, the liquid was discarded and the plate dried. Biotin-labeled antibody working fluid (100 $\mu \mathrm{l}$; $1 \mathrm{X}$ antibody) was added to each well and incubated at $37^{\circ} \mathrm{C}$ for $1 \mathrm{~h}$. This was discarded and the plate was washed with 0.01 M PBS three times. Avidin-Biotin-Peroxidase Complex working solution (100 $\mu \mathrm{l}$; $1 \mathrm{X}$ solution) was added to each well and the plate was incubated at room temperature for $1 \mathrm{~h}$. 
This was discarded and the plate was shaken dry. TMB color developing agent $(90 \mu \mathrm{l})$ was added to each well, incubated at $37^{\circ} \mathrm{C}$ in the dark for $30 \mathrm{~min}$ and then $50 \mu \mathrm{l}$ termination solution was added. The optical density value was measured using a SpectraMax ${ }^{\circledR}$ microplate reader (Molecular Devices, LLC) at $450 \mathrm{~nm}$. All the reagents were from the following ELISA kits: Tumor necrosis factor (TNF)- $\alpha$ (cat. no. RTA00: R\&D Systems, Inc.), IL-6 (cat. no. R6000B; R\&D Systems, Inc.) and KIM-1 (cat. no. ab119597; Abcam).

TUNEL-DAPI double staining. According to the instructions of the TUNEL kit (Roche Diagnostics). The $4 \mu \mathrm{m}$ thick paraffin sections were dewaxed in the oven at $60^{\circ} \mathrm{C}$ for $2 \mathrm{~h}$, washed with xylene at room temperature, dehydrated in a descending alcohol series $(100,90,80$ and 75\%) and washed three times with PBS at room temperature. Cell permeability solution was added for $8 \mathrm{~min}$, and $500 \mu \mathrm{l}$ TUNEL reaction mixture was added (50 $\mu \mathrm{l}$ TdT and $450 \mu 1$ fluorescein-labeled $\mathrm{dUTP})$ at $37^{\circ} \mathrm{C}$ for $1 \mathrm{~h}$ in the dark box. After DAPI staining (10 $\mu \mathrm{g} / \mathrm{ml}$; at room temperature for $5 \mathrm{~min})$, the cells were sealed. Under fluorescence microscopy, 10 high-power microscope fields were randomly selected from each glass slide to count the number of apoptotic cells and calculate the apoptosis rate using the following formula: Apoptosis rate $/ \%=($ number of positive cells/total number of cells) x100\%.

Western blot analysis of NLRP3 expression. Kidney tissues were extracted, and RIPA (1\% PMSF) tissue lysate (Beyotime Institute of Biotechnology) was added and the samples were homogenized with a tissue grinder to extract the total protein. A BCA protein concentration kit was used to measure the total protein concentration. Equal amounts of protein extract $(40 \mu \mathrm{g})$ were loaded per lane and separated via $8-12 \%$ SDS-PAGE followed by membrane transfer to polyvinylidene fluoride membranes (EMD Millipore) and blocking in 5\% skimmed milk powder for $15 \mathrm{~min}$ at room temperature. The primary antibody was added and incubated overnight in a $4^{\circ} \mathrm{C}$ refrigerator with agitation. After washing with $1 \mathrm{X}$ TBST $(0.1 \%$ Tween-20; cat. no. ST671; Beyotime Institute of Biotechnology), the membrane was incubated with the secondary antibody at room temperature for $2 \mathrm{~h}$. Protein bands were visualized using an ECL kit (Sparkjade Science Co., Ltd.). $\beta$-actin was used as an internal reference. ImageJ software (version 1.8.0; National Institutes of Health) was used to quantify the western blot bands. Primary antibodies against NLRP3 (1:1,000; cat. no. ab214185; Abcam), HIF1- $\alpha$ (1:1,000; cat. no. 14179; Cell Signaling Technology, Inc.), cleaved caspase-3 (1:1,000; cat. no. ab49822; Abcam) and $\beta$-actin (1:5,000; cat. no. 60008-1-Ig; ProteinTech Group, Inc.) were used in the present study. The secondary antibodies included horseradish peroxidase (HRP)-conjugated goat anti-mouse IgG (1:3,000; cat. no. SA00001-1; ProteinTech Group, Inc.) and HRP-conjugated goat anti-rabbit $\operatorname{IgG}(1: 3,000$; cat. no. SA00001-2; ProteinTech Group, Inc.).

$R T$ - $q P C R$. Renal tissue (50 mg) was taken, RNA was extracted using TRIzol ${ }^{\circledR}$ (Tiangen Biotech Co., Ltd.). cDNA was obtained through reverse transcription of $500 \mathrm{ng}$ RNA using a reverse transcription kit (Tiangen Biotech Co., Ltd.) at $70^{\circ} \mathrm{C}$ for $5 \mathrm{~min}, 37^{\circ} \mathrm{C}$ for $5 \mathrm{~min}, 42^{\circ} \mathrm{C}$ for $60 \mathrm{~min}, 70^{\circ} \mathrm{C}$ for $10 \mathrm{~min}$. The
RT-qPCR reaction was performed by taking $5 \mu 1 \mathrm{cDNA}$ (1:5 diluted cDNA solution) and reacting it in MicroAmp ${ }^{\mathrm{TM}}$ Fast Optical 96-well reaction plates (Applied Biosystems; Thermo Fisher Scientific, Inc.), with SYBR ${ }^{\circledR}$ Premix Ex Taq ${ }^{\mathrm{TM}}$ (Takara Bio Inc.). The thermocycling conditions were: $94^{\circ} \mathrm{C}$ for $5 \mathrm{~min}$, $95^{\circ} \mathrm{C}$ for $30 \mathrm{sec}$; then, 40 cycles at $59^{\circ} \mathrm{C}$ for $30 \mathrm{sec}, 72^{\circ} \mathrm{C}$ for $30 \mathrm{sec}$ and $72^{\circ} \mathrm{C}$ for $10 \mathrm{~min}$; and a final extension at $65-95^{\circ} \mathrm{C}$ for $15 \mathrm{~min}$. The results were analyzed using RQ Manager for SDS 2.3 with GenEx 7.0 (MultiD Analyses AB). The following primers were used: NLRP3, forward: 5'-GGAGTGGATAGG TTTGCTGG-3' and reverse: 5'-GGTGTAGGGTCTGTTGAG GT-3'; housekeeping gene GAPDH, forward: 5'-TGCATCCTG CACCACCAACTGC-3' and reverse: 5'-ACAGCCTTGGCA GCACCAGTGG-3'. The $2^{-\Delta \Delta \mathrm{Cq}}$ method was used to calculate the relative mRNA expression (24).

Immunohistochemical staining. Paraffin-embedded sections (4- $\mu \mathrm{m}$ thick) were dewaxed and rehydrated using the GTVision $^{\text {TM }}$ III anti-rat/rabbit universal immunohistochemical detection kit (cat. no. GK500710; Gene Tech Co., Ltd.) according to the manufacturer's protocol. Antigen retrieval was performed in $0.01 \mathrm{M}$ citrate buffer at $100^{\circ} \mathrm{C}$ for $6 \mathrm{~min}$. Following cooling, the sections were washed three times in $0.01 \mathrm{M}$ PBS for $5 \mathrm{~min}$ each. Subsequently, the sections were incubated with $3 \% \mathrm{H}_{2} \mathrm{O}_{2}$ at room temperature for $10 \mathrm{~min}$. The sections were incubated with a primary polyclonal antibody targeted against NLRP3 (cat. no. ab214185, 1:200; Abcam) at $4^{\circ} \mathrm{C}$ overnight, and then with a secondary horseradish peroxidase-conjugated goat anti-rabbit IgG antibody for $30 \mathrm{~min}$ at room temperature, according to the rabbit polymer detection system (cat. no. PV-6001; OriGene Technologies, Inc.). The sections were stained with DAB reagent $(1 \mathrm{X})$ for $3 \mathrm{~min}$ at room temperature, counterstained with hematoxylin for $3 \mathrm{~min}$ at room temperature and washed by tap water. Stained sections were observed using a Leica DM 6000 B light microscope (Leica Microsystems $\mathrm{GmbH}$ ). Brown staining indicated a positive reaction. ImageJ software (version 1.8.0; National Institutes of Health) was used for analysis.

Establishment of the oxygen and glucose deprivation (OGD) model. The OGD model was constructed by replacing RPMI 1640 medium with Earle's balanced salt solution (EBSS; HyClone; Cytiva) with $95 \% \mathrm{~N}_{2}$ and $5 \% \mathrm{CO}_{2}$. NRK cells $\left(5 \times 10^{5}\right)$ were cultured in the hypoxic incubator at $37^{\circ} \mathrm{C}$ for $6 \mathrm{~h}$, after which hypoxia was terminated and RPMI 1640 medium with $10 \% \mathrm{FBS}$ was added for $18 \mathrm{~h}$ for follow-up experiments.

CCK- 8 assay. The cell density of NRK cells in the logarithmic growth phase was adjusted to $1 \times 10^{5}$. Cell suspension $(100 \mu 1$ per well) was inoculated in 96-well plates, and the CCK-8 reagents (Beyotime Institute of Biotechnology) were added according to the manufacturer's protocols. Each group was set up with three duplicate wells and cultured at $37^{\circ} \mathrm{C}$ for $4 \mathrm{~h}$. Then, the absorbance was measured at $450 \mathrm{~nm}$ using the Infinite M200 PRO (Tecan Group, Ltd.).

Statistical analysis. Data are presented as the mean \pm standard error of the mean. The significance of the differences in mean values among groups was examined by one-way ANOVA followed by Duncan's multiple range tests. SPSS 20.0 (IBM, 
Corp.) and GraphPad Prism 6 software (GraphPad Software, Inc.) were used for statistical analyses. $\mathrm{P}<0.05$ was considered to indicate a statistically significant difference. All the experiments were performed in triplicate.

\section{Results}

TMP alleviates renal tubular pathological injury and improves renal function in rats with renal I/R. PAS staining showed complete glomerular and renal tubules in the sham operation group, with no obstruction in the lumen and no obvious morphological abnormalities, while in the I/R group the renal tubules showed extensive necrosis of epithelial cells, obvious brush border membrane fraction and vacuolar tubules. In the I/R+TMP group, the necrosis of renal tubular epithelial cells was reduced, and the course of disease had slowed down. A small number of exfoliated cells could be seen at the brush borders of renal tubules, and some hollow vacuoles were observed in the renal tubules (Fig. 1A). Double-blind analysis of tubular injury by pathologists revealed a significant decrease in tubular injury scores in TMP-treated rats after renal I/R (P<0.05; Fig. 1B).

The level of KIM-1 was detected using an ELISA assay, compared with in the Sham group the level of KIM-1 was significantly increased in the I/R group and elevated KIM-1 was significantly reduced in the I/R+TMP group $(\mathrm{P}<0.05$; Fig. $1 \mathrm{C})$. The serum creatinine and blood urea nitrogen test results showed that, compared with the Sham group, serum creatinine and urea nitrogen in the $\mathrm{I} / \mathrm{R}$ group and $\mathrm{I} / \mathrm{R}+\mathrm{TMP}$ group were both increased $(\mathrm{P}<0.05)$, indicating that renal function was impaired by renal I/R. Compared with the I/R group, serum creatinine and blood urea nitrogen in the I/R+TMP group were significantly decreased $(\mathrm{P}<0.05$; Fig. $1 \mathrm{D}$ and $\mathrm{E})$, suggesting that TMP may reduce renal functional injury.

The ELISA assay results for the inflammatory cytokines TNF- $\alpha$ and IL- 6 showed that, compared with the Sham group, the levels of TNF- $\alpha$ and IL- 6 in the I/R and I/R+TMP groups were increased $(\mathrm{P}<0.05)$, and significantly decreased in the $\mathrm{I} / \mathrm{R}+\mathrm{TMP}$ group compared with the $\mathrm{I} / \mathrm{R}$ group $(\mathrm{P}<0.05$; Fig. $1 \mathrm{~F}$ and $\mathrm{G}$ ), indicating that TMP can reduce the production of inflammatory cytokines.

$T M P$ reduces renal tubular apoptosis in rats with renal $I / R$. After TUNEL-DAPI staining, it was found that compared with the Sham group, the amount of renal tubular cell apoptosis in the I/R and I/R+TMP groups was significantly increased. Compared with the I/R group, the amount of renal tubular cell apoptosis in the I/R+TMP group was significantly reduced after TMP treatment $(\mathrm{P}<0.05$; Fig. $2 \mathrm{~A}$ and $\mathrm{B})$.

Meanwhile, the expression level of the apoptotic protein caspase 3 in rat kidney tissues was detected. The expression of caspase 3 was significantly increased in the $I / R$ and I/R+TMP groups. However, compared with the I/R group, the protein expression of caspase 3 in the $\mathrm{I} / \mathrm{R}+\mathrm{TMP}$ group was significantly reduced after TMP treatment $(\mathrm{P}<0.05$; Fig. 2C).

TMP reduces the expression of NLRP3 in renal tissues of renal I/R rats. Western blot analysis of NLRP3 expression in the kidney tissues of rats in each group showed that compared with the Sham group, NLRP3 protein expression in the I/R and I/R+TMP groups significantly increased. NLRP3 protein expression significantly decreased in the I/R+TMP group compared with in the I/R group $(\mathrm{P}<0.05$; Fig. $3 \mathrm{~A})$.

According to RT-qPCR, the expression of NLRP3 mRNA in rat kidney tissues increased. Compared with the Sham group, the expression of NLRP3 mRNA in the I/R and $\mathrm{I} / \mathrm{R}+\mathrm{TMP}$ groups increased. NLRP3 mRNA expression was reduced in the I/R+TMP group compared with that in the $\mathrm{I} / \mathrm{R}$ group $(\mathrm{P}<0.05$; Fig. 3B). The PCR results were consistent with the western blot analysis measuring protein expression.

After immunohistochemical staining, it was found that compared with the Sham group, the positive expression of NLRP3 in renal tissues from the I/R and I/R+TMP groups significantly increased. Besides renal tubules, NLRP3 was positively expressed in infiltrating inflammatory cells in the renal interstitium in the $I / R$ group and the number of infiltrated inflammatory cells was increased, which was markedly decreased in the I/R+TMP group. Compared with the $\mathrm{I} / \mathrm{R}$ group, the positive rate of NLRP3 expression in renal tissues of the I/R+TMP group was notably reduced (Fig. 3C). The immunohistochemical results showed that TMP could not only reduce the expression of NLRP3 in renal tubules, but also mitigate renal tissue damage by reducing the infiltration of inflammatory cells.

TMP may suppress NLRP3 expression induced by hypoxia and improve cell viability in rat NRK-52E cells. The response to hypoxia at the cellular level relies on the activity of the transcription factor family, HIF. Therefore, the effect of TMP on HIF-1 $\alpha$ was assessed under hypoxia. HIF-1 $\alpha$ was significantly increased after treatment with OGD, and significantly reduced after treatment with TMP $(\mathrm{P}<0.05$; Fig. 4A). The level of NLRP3 expression was significantly increased after OGD, and reduced after treatment with TMP, which was consistent with the changes in HIF- $1 \alpha$ expression $(\mathrm{P}<0.05$; Fig. 4B). At the same time, cell viability was significantly decreased after OGD treatment, and significantly increased after TMP treatment $(\mathrm{P}<0.05$; Fig. 4C).

\section{Discussion}

TMP can improve microcirculation, prevent platelet aggregation and activate blood circulation (25). Studies have reported that TMP has a cardioprotective effect in myocardial I/R injury, mainly through antioxidant, anti-inflammatory and antiapoptotic activities, and improves coronary blood flow and myocardial metabolism by enhancing the expression of $\mathrm{NO}$ via upregulating the expression of NOS (26). However, the mechanism by which TMP alleviates RIPI is still unclear. The main pathological mechanisms of kidney I/R involves free radicals, intracellular calcium overload (27), inflammatory reactions and apoptosis (28). Therefore, the present study focused on the effect of TMP on the NLRP3 inflammasome and apoptosis.

Previous studies have demonstrated that inflammation is involved in the process of I/R-induced kidney damage. Chen et al (29) found that TMP can inhibit liver inflammation by reducing the production of TNF- $\alpha$ and IL-6, reactive oxygen species (ROS) generation and the activation of NF- $\mathrm{kB}$. 
A Sham
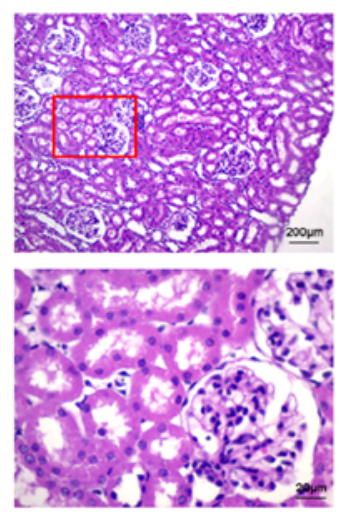

C

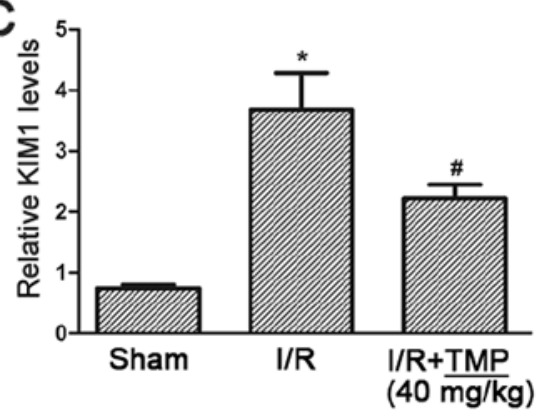

F

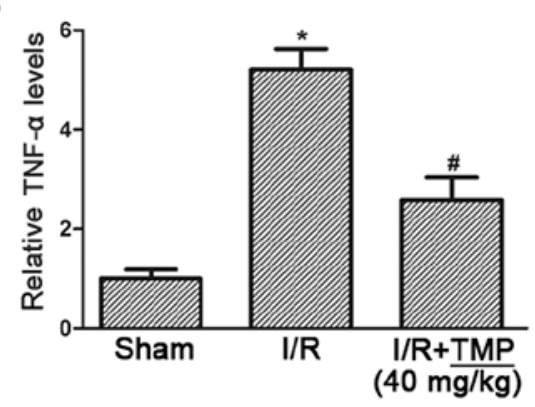

I/R
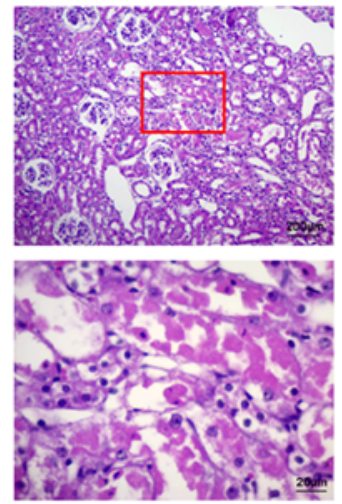

$\mathrm{D}$
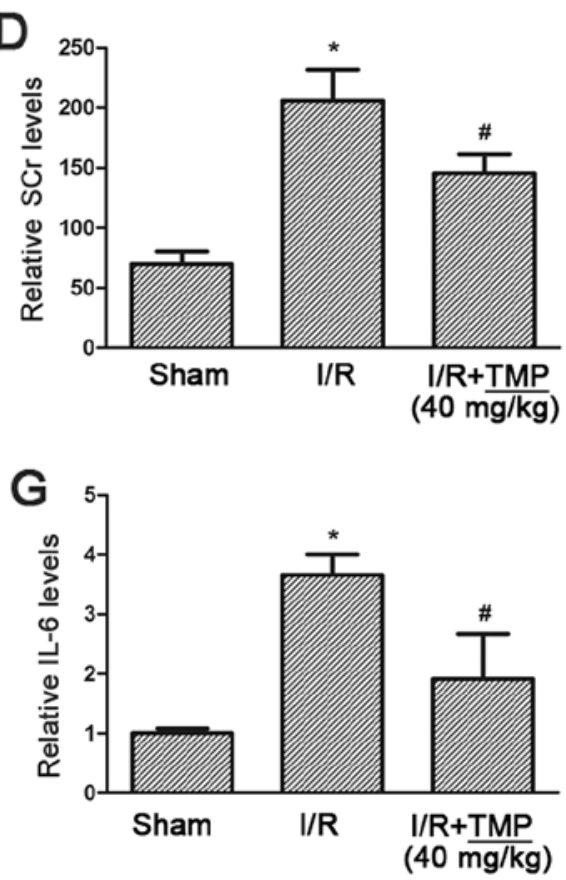

B
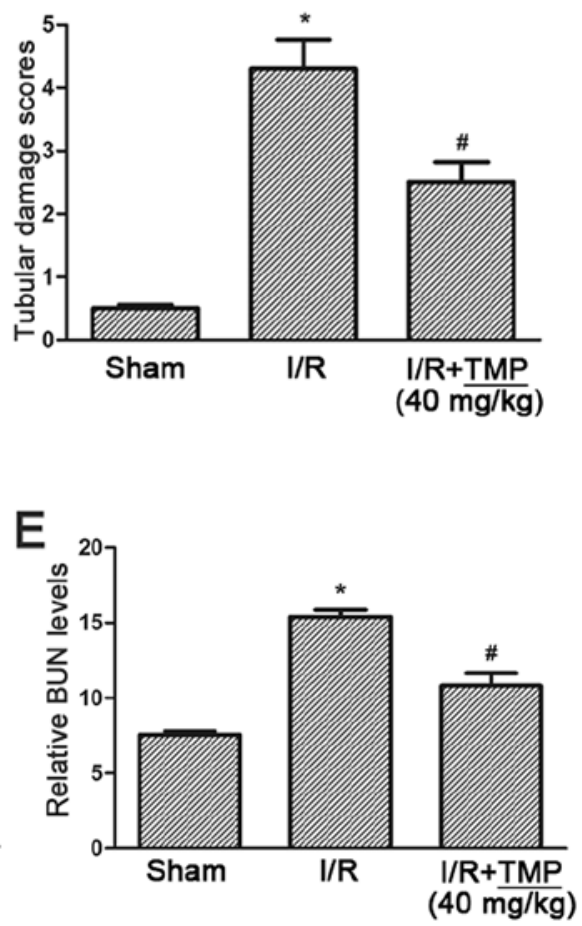

Figure 1. TMP alleviates renal tubular pathological injury and improves renal function in rats with renal I/R. (A) Photomicrographs of periodic acid-Schiff staining showing typical renal tubular injury in Sham, I/R and I/R+TMP rats, red boxes highlight the corresponding areas of the high-power images. (B) Summarized data showing the renal tubular injury score in each group. (C) The ELISA results showing the level of KIM-1 in each group. (D and E) SCr and BUN levels in each group were measured by a biochemical analyzer. (F and G) The ELISA results showing the levels of the inflammatory cytokines TNF- $\alpha$ and IL-6 in each group. " $\mathrm{P}<0.05$ vs. Sham rats; ${ }^{~} \mathrm{P}<0.05$ vs. I/R rats. I/R, ischemia-reperfusion; TMP, tetramethylpyrazine; KIM-1, kidney injury molecule 1 ; TNF- $\alpha$, tumor necrosis factor- $\alpha$; IL-, interleukin; SCr, serum creatinine; BUN, blood urea nitrogen.

Bai et al (30) reported that TMP inhibits inflammatory cell activation and the production of proinflammatory cytokines, and has been shown to alleviate cerebral ischemia injury. Consistent with previous findings, the present study found that after treatment with TMP, the renal tubular injury scores of renal I/R rats were significantly reduced (Fig. 1A and B), and KIM-1 was also significantly decreased (Fig. 1C). The expression levels of inflammatory factors were decreased (Fig. 1F and G), suggesting that TMP can significantly reduce the inflammatory injury caused by renal I/R.

Apoptosis plays an important role in RIPI. A number of studies have demonstrated that TMP can reduce cell apoptosis. Feng et al (31) found that TMP could alleviate RIPI by inhibiting apoptosis. Qing et al (32) reported that TMP can participate in the Akt/transcription factor Nrf2 signaling pathway to promote angiogenesis and reduce apoptosis to improve multiterritory perforator flap survival in reconstructive surgery. The present results showed that after treatment with TMP, renal tissue apoptosis significantly decreased; and the expression levels of apoptosis-related proteins were also reduced. These results indicated that TMP could inhibit apoptosis (Fig. 2A and C).

Numerous studies have reported that TMP can inhibit the inflammatory response. The inflammatory response is a complex process, and there are a number of factors that cause inflammation. Therefore, the current study focused on the relationship between TMP and NLRP3 inflammasome. Previous studies have demonstrated that NLRP3 is associated with cardiovascular and cerebrovascular diseases, acute lung injury, hepatitis cirrhosis and kidney injury. Zhang et al (33) reported that lipopolysaccharide (LPS) effectively activates the NLRP3 inflammasome/caspase 1 pathway, causing liver cells to produce the inflammatory cytokine IL-1 $\beta$. However, TMP blocks the 

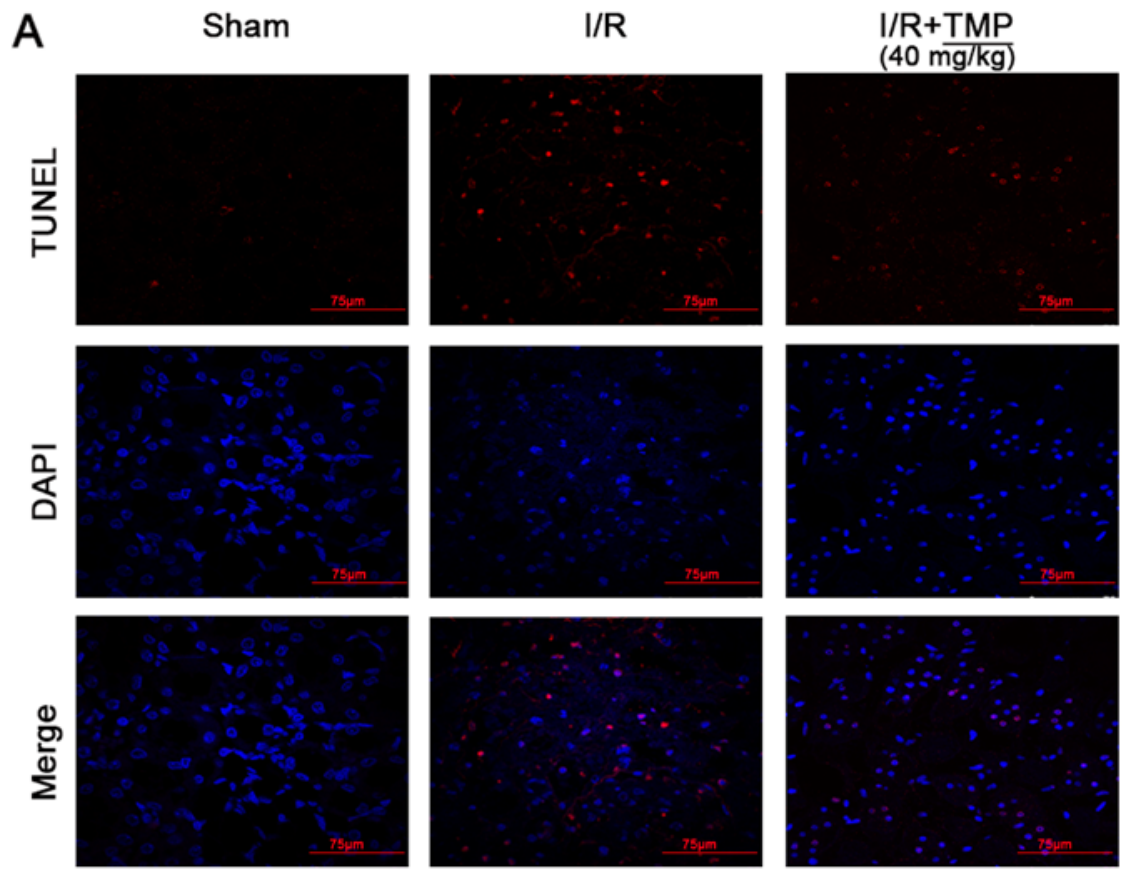

B
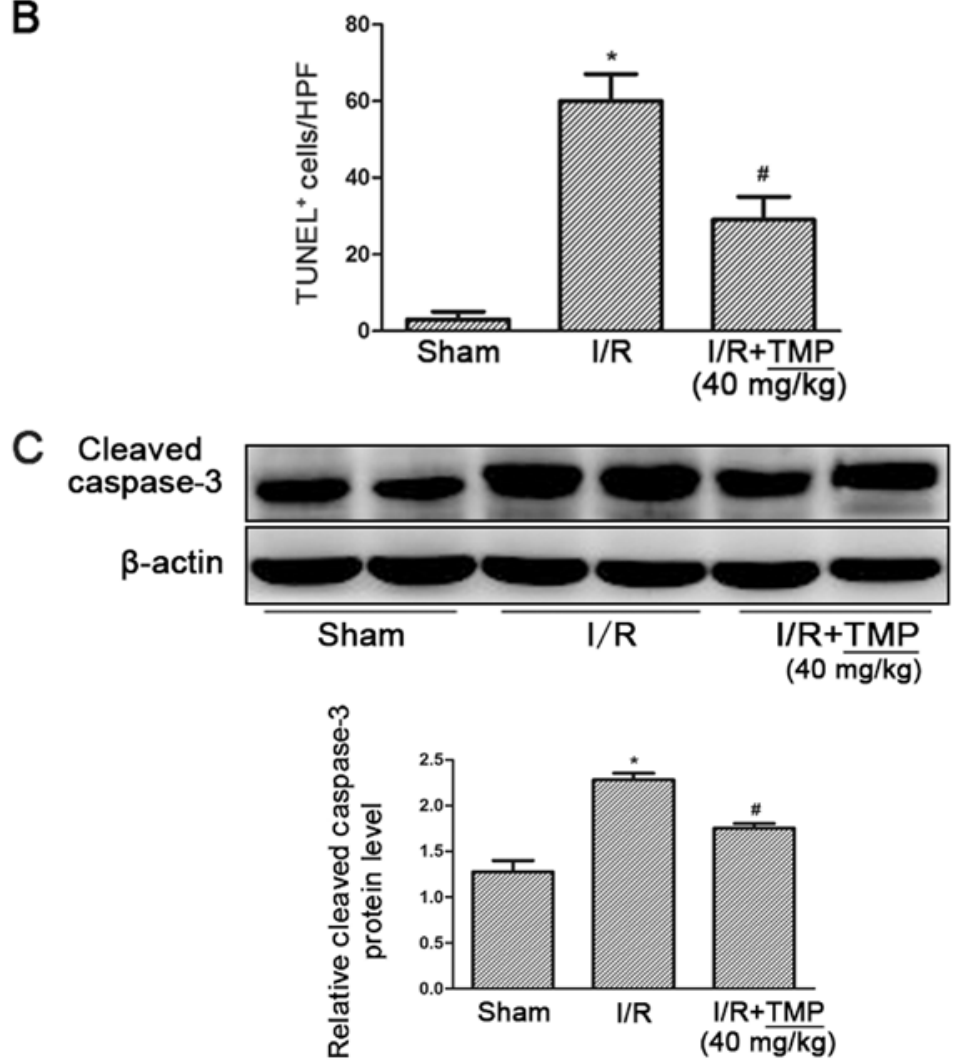

Figure 2. TMP improves renal function in renal I/R rats. (A) TUNEL-DAPI staining showing apoptosis in Sham, I/R and I/R+TMP rats. (B) Statistical results of TUNEL-DAPI-stained positive cells. (C) Representative western blotting image and summarized data showing the change in the expression of cleaved caspase- 3 in each group of rats. ${ }^{~} \mathrm{P}<0.05$ vs. Sham rats; ${ }^{*} \mathrm{P}<0.05$ vs. I/R rats. I/R, ischemia-reperfusion; TMP, tetramethylpyrazine; HPF, high-power field.

LPS-activated NLRP3 inflammasome signaling pathway, which is achieved by inhibiting toll-like receptor (TLR) 4 and thereby reducing the production of hepatocyte IL-1 $\beta$. Wu et al (34) suggested that TMP may target liver stem cells via the platelet derived growth factor- $\beta$ receptor/NLRP3/caspase-1 pathway to reduce the inflammatory response in liver fibrosis. The present study also demonstrated that TMP could inhibit the NLRP3 inflammasome during renal $\mathrm{I} / \mathrm{R}$, at both the gene and protein levels, as verified in vivo and in vitro.

The response to hypoxia at the cellular level relies on the activity of the HIF transcription factor family (16). Huang et al (35) reported that when myocardial I/R occurs, the expression of HIF-1 $\alpha$ is the initiating factor of the body's endogenous protective mechanism, which can promote the 
A
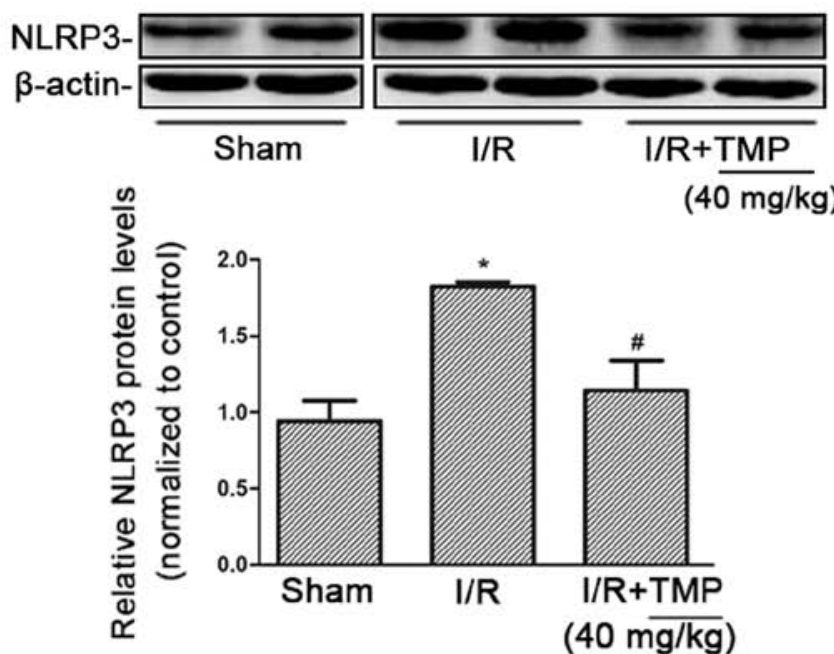

Sham

$(40 \mathrm{mg} / \mathrm{kg})$

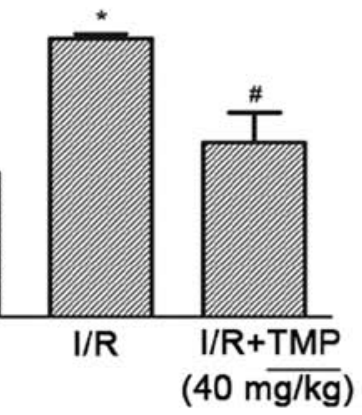

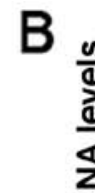

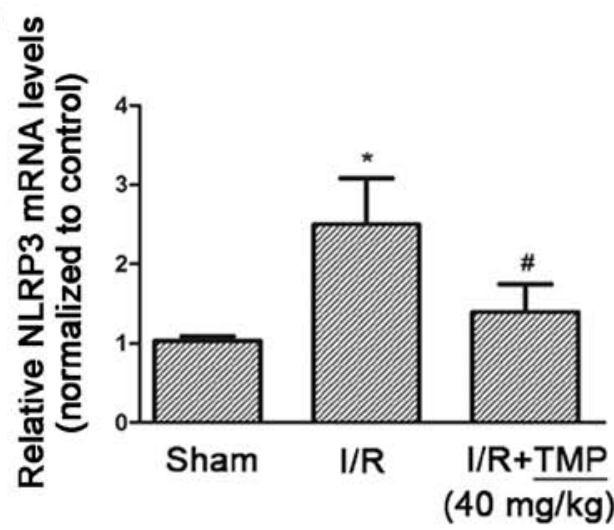

(40 $\mathrm{mg} / \mathrm{kg}$ )
C
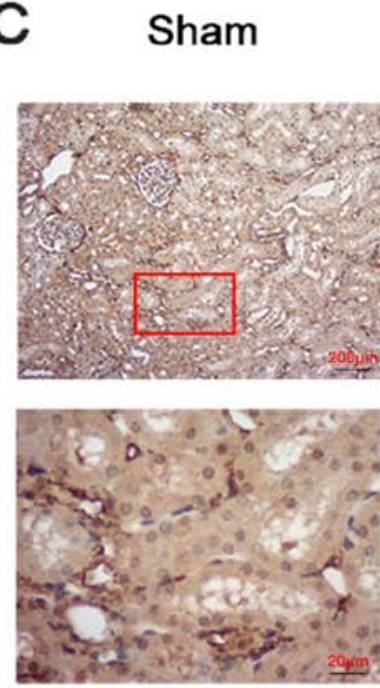

I/R
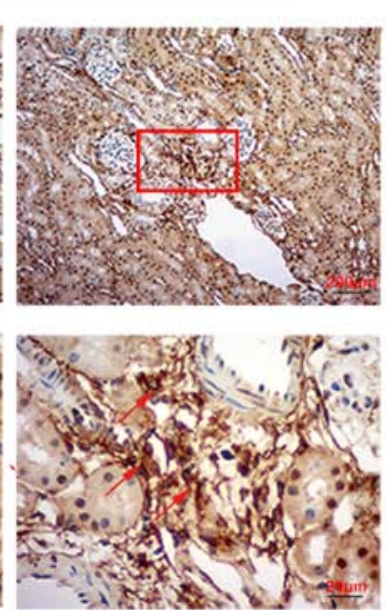

I/R+TMP $(40 \mathrm{mg} / \mathrm{kg})$
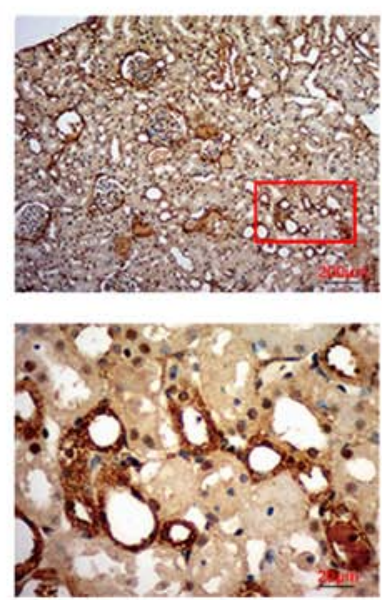
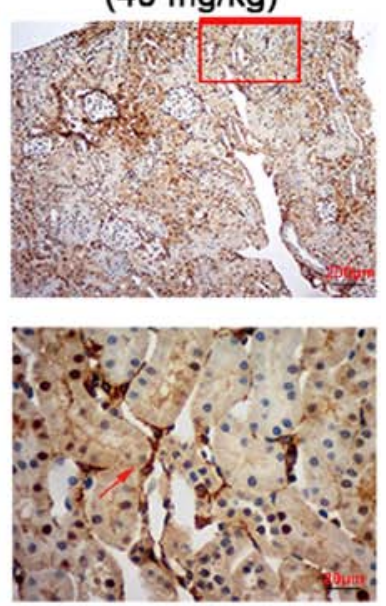

Figure 3. TMP reduces the expression of NLRP3 in renal tissues from renal I/R rats. (A) Representative western blotting image and summarized data showing the expression of NLRP3 in the kidney tissues of rats in the Sham, I/R and I/R+TMP groups. (B) Reverse transcription-quantitative PCR was used to detect NLRP3 mRNA expression in the kidney tissues of rats in each group. (C) Immunohistochemical staining showing the expression of NLRP3 in renal tissues in each group. The red arrows indicate the positive expression of NLRP3 in infiltrating inflammatory cells. Red boxes highlight the corresponding area of the high-power images. " $\mathrm{P}<0.05$ vs. Sham rats; ${ }^{\mathrm{P}}<0.05$ vs. I/R rats. I/R, ischemia-reperfusion; TMP, tetramethylpyrazine; NLRP3, NACHT, LRR and PYD domains-containing protein.

course of myocardial I/R. HIF-1 $\alpha$ plays a primary role in the body's inflammatory response, which includes inflammatory cell activation in various pathological conditions (16). In an HIF-1 $\alpha$-dependent manner, the TLR7/8-mediated inflammatory reaction results in activation of the NLRP3 inflammasome via activation of xanthine oxidase, which produces uric acid and ROS (36). NLRP3 inflammasome activity could be sustained via the cyclic AMP (cAMP)/protein kinase A/cAMP response element/HIF-1 $\alpha$ pathway as a result of adenosine activity (37). Under pathological conditions of venous thrombosis, the expression of NLRP3 is regulated by HIF-1 $\alpha$ (38). A novel HIF-1 $\alpha$-induced eotaxin pathway identifies an unknown connection between hypoxia and the regulation of the severity of inflammation regulated by TLR4 in asthma (39). Hypoxia and elevated HIF-1 $\alpha$ promotes inflammatory signals, including NLRP3/inflammasome/caspase-1 activation in fat-laden hepatocytes (40). In the present study, the effect of TMP on HIF-1 $\alpha$ was examined under hypoxia.
It was also demonstrated that HIF-1 $\alpha$ expression increased in NRK cells treated with OGD, while the levels of HIF-1 $\alpha$ were significantly reduced after treatment with TMP. This is consistent with the changes in NLRP3 expression. Therefore, it is suggested that TMP can reduce NLPR3 by reducing HIF-1 $\alpha$ expression.

At present, there are no effective drug treatments and renal replacement therapy is used to prolong the survival of patients with renal I/R nephropathy. Some drugs have been reported to have action in only animal models of renal I/R. Hydroxychloroquine attenuated renal injury via downregulation of cathepsin (CTS) B and CTSL-mediated NLRP3 inflammasome activation (41). Isoquercitrin has been demonstrated to attenuate RIRI through its antioxidative, anti-inflammatory and antiapoptotic effects to preserve renal function (42). In addition, recent studies indicated that cordycepin was effective for renal I/R (43). These drugs, including TMP, have been shown to regulate 

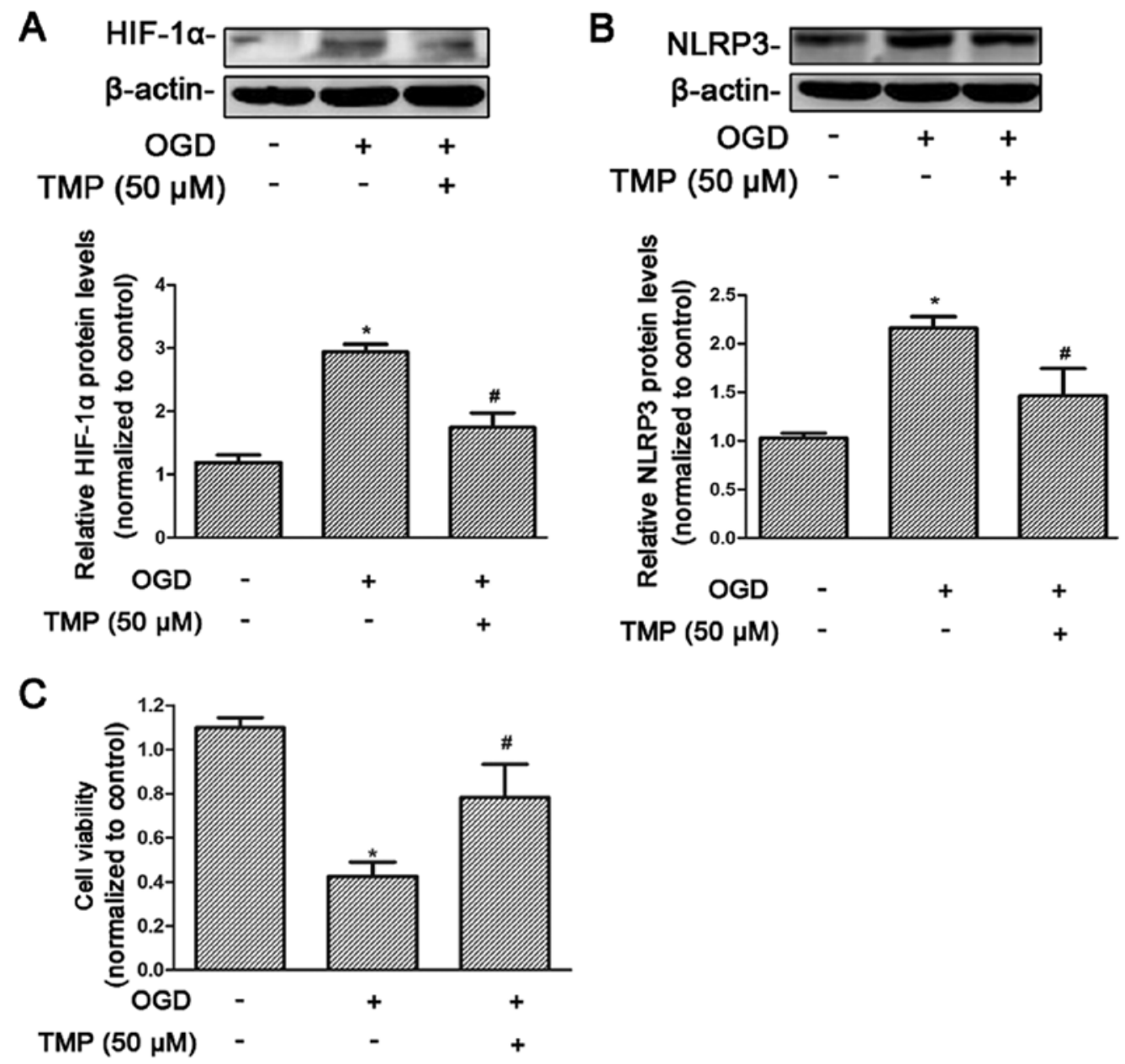

Figure 4. TMP can reverse the damage of OGD in NRK cells, reduce the expression levels of HIF-1 $\alpha$ and NLRP3 and increase cell viability. (A and B) Representative western blotting image and summarized data showing the expression of HIF-1 $\alpha$ and NLRP3 with and without treatment with TMP. (C) CCK- 8 was used to detect the viability of NRK cells treated with OGD and TMP. ${ }^{*} \mathrm{P}<0.05$ vs. control group; ${ }^{\#} \mathrm{P}<0.05$ vs. I/R rats. TMP, tetramethylpyrazine; NLRP3, NACHT, LRR and PYD domains-containing protein; OGD, oxygen and glucose deprivation; HIF-1 $\alpha$, hypoxia-inducible factor 1- $\alpha$

inflammation, apoptosis and oxidative stress. However, no study has compared their efficacy in the treatment of $I / R$ in an animal model. At present, an ongoing study in our research group is investigating the efficacy of TMP compared with erythropoietin. ROS are involved in the activation of NLRP3 inflammation (44). In the present study, the effect of TMP on ROS was not investigated, and only the alterations to NLRP3 expression levels were shown rather than the activation of the NLRP3 inflammasome in in vivo experiments. We will further explore the specific mechanism of TMP in the reduction of hypoxia-induced elevation of NLRP 3 in vitro and investigate the relationship between NLRP3 and HIF- $1 \alpha$ in order to understand the interaction between hypoxic injury and innate immune response.

In conclusion, the present study demonstrated that TMP can reduce protein expression of NLRP3 in renal tissue and renal tubular cell apoptosis, improve renal tubule pathological injury, improve kidney serum creatinine and blood urea nitrogen levels, and improve renal function to relieve RIPI. This study represents a novel idea, broadening the uses of traditional Chinese medicines. With increased understanding of the mechanism of action of TMP, it is hoped that it may be applied to the treatment of a wide range of kidney diseases.

\section{Acknowledgements}

Not applicable.

\section{Funding}

The present study was supported by the National Nature Science Foundation of China (grant no. 81500557); the Foundation for Excellent Young and Middle-Aged Scientists of Shandong Province (grant no. BS2014YY018); Shandong Natural Science Fund of Shandong Province (grant no. ZR2017BH055); Undergraduate Innovation and Entrepreneurship Training Program of Shandong Province (grant no. 201910440028).

\section{Availability of data and materials}

The datasets used and/or analyzed during the current study are available from the corresponding author on reasonable request.

\section{Authors' contributions}

WS, AL and ZW were responsible for designing the study, collecting the data, performing the statistical analysis and 
drafting the manuscript. XS, MD, FQ, LW and YZ collected the data, performing the statistical analysis and conducted the literature search. PD supervised the project, helped to design the study, analyzed the data and wrote the manuscript. All authors read and approved the final manuscript.

\section{Ethics approval and consent to participate}

The current study was approved by the Animal Ethics Committee of Binzhou Medical University (approval no. 2015-008).

\section{Patient consent for publication}

Not applicable.

\section{Competing interests}

The authors declare that they have no competing interests.

\section{References}

1. Malek M and Nematbakhsh M: Renal ischemia/reperfusion injury; From pathophysiology to treatment. J Renal Inj Prev 4: 20-27, 2015.

2. Kellum JA, Unruh ML and Murugan R: Acute kidney injury. BMJ Clin Evid 2011: 2001, 2011.

3. Sethi K, Rao K, Bolton D, Patel O and Ischia J: Targeting HIF-1 $\alpha$ to prevent renal ischemia-reperfusion injury: Does it work? Int J Cell Biol 2018: 9852791, 2018.

4. Guo Z, Yu S, Chen X, Ye R, Zhu W and Liu X: NLRP3 is involved in ischemia/reperfusion injury. CNS Neurol Disord Drug Targets 15: 699-712, 2016.

5. Minutoli L, Puzzolo D, Rinaldi M, Irrera N, Marini H, Arcoraci V, Bitto A, Crea G, Pisani A, Squadrito F, et al: ROS-mediated NLRP3 inflammasome activation in brain, heart, kidney, and testis ischemia/reperfusion injury. Oxid Med Cell Longev 2016 2183026, 2016

6. Shao BZ, Xu ZQ, Han BZ, Su DF and Liu C: NLRP3 inflammasome and its inhibitors: A review. Front Pharmacol 6: 262, 2015.

7. Latz E: The inflammasomes: Mechanisms of activation and function. Curr Opin Immunol 22: 28-33, 2010.

8. Mezzaroma E, Toldo S, Farkas D, Seropian IM, Tassell BW, Salloum FN, Kannan HR, Menna AC, Voelkel NF and Abbate A: The inflammasome promotes adverse cardiac remodeling following acute myocardial infarction in the mouse. Proc Natl Acad Sci USA 108: 19725-19730, 2011.

9. Sandanger $\varnothing$, Ranheim T, Vinge LE, Bliksøen M, Alfsnes K, Finsen AV, Dahl CP, Askevold ET, Florholmen G, Christensen G, et al: The NLRP3 inflammasome is up-regulated in cardiac fibroblasts and mediates myocardial ischemia-reperfusion injury. Cardiovasc Res 99: 164-174, 2013.

10. Xin R, Sun X, Wang Z, Yuan W, Jiang W, Wang L, Xiang Y, Zhang H, Li X, Hou Y, et al: Apocynin inhibited NLRP3/XIAP signalling to alleviate renal fibrotic injury in rat diabetic nephropathy. Biomed Pharmacother 106: 1325-1331, 2018.

11. Hou Y, Lin S, Qiu J, Sun W, Dong M, Xiang Y, Wang L and Du P: NLRP3 inflammasome negatively regulates podocyte autophagy in diabetic nephropathy. Biochem Biophys Res Commun 521: 791-798, 2020.

12. Wu R, Liu X, Yin J, Wu H, Cai X, Wang N, Qian Y and Wang F: IL-6 receptor blockade ameliorates diabetic nephropathy via inhibiting inflammasome in mice. Metabolism 83: 18-24, 2018.

13. Wang F, Yin J, Lin Y, Zhang F, Liu X, Zhang G, Kong Y, Lu Z, Wu R, Wang N, et al: IL-17C has a pathogenic role in kidney ischemia/reperfusion injury. Kidney Int 97: 1219-1229, 2020.

14. Wen Y, Liu YR, Tang TT, Pan MM, Xu SC, Ma KL, Lv LL, Liu $\mathrm{H}$ and Liu BC: mROS-TXNIP axis activates NLRP3 inflammasome to mediate renal injury during ischemic AKI. Int J Biochem Cell Biol 98: 43-53, 2018.

15. Nangaku M and Eckardt KU: Hypoxia and the HIF system in kidney disease. J Mol Med (Berl) 85: 1325-1330, 2007.

16. Batie M, Druker J, D'Ignazio L and Rocha S: KDM2 family members are regulated by HIF-1 in hypoxia. Cells 6: 8, 2017.
17. Ichimura T, Bonventre JV, Bailly V, Wei H, Hession CA, Cate RL and Sanicola M: Kidney injury molecule-1 (KIM-1), a putative epithelial cell adhesion molecule containing a novel immunoglobulin domain, is up-regulated in renal cells after injury. J Biol Chem 273: 4135-4142, 1998.

18. Lv L, Jiang SS, Xu J, Gong JB and Cheng Y: Protective effect of ligustrazine against myocardial ischaemia reperfusion in rats: The role of endothelial nitric oxide synthase. Clin Exp Pharmacol Physiol 39: 20-27, 2012.

19. Chen HY, Xu DP, Tan GL, Cai W, Zhang GX, Cui W, Wang JZ, Long C, Sun YW, Yu P, et al: A potent multi-functional neuroprotective derivative of tetramethylpyrazine. J Mol Neurosci 56: 977-987, 2015.

20. Tuttle RS, Marmelstein L, Trad T, Reddy S and Radley T: In vitro uterine response to tetramethylpyrazine, the active constituent of Chung Chong (a traditional Chinese medicine). Am J Obstet Gynecol 161: 1319-1323, 1989.

21. Yang WJ, Li YR, Gao H, Wu XY, Wang XL, Wang XN, Xiang L, Ren DM, Lou HX and Shen T: Protective effect of the ethanol extract from Ligusticum chuanxiong rhizome against streptozotocin-induced diabetic nephropathy in mice. J Ethnopharmacol 227: 166-175, 2018.

22. Luan Y, Liu J, Liu X, Xue X, Kong F, Sun C, Wang J, Liu L and Jia H: Tetramethypyrazine inhibits renal cell carcinoma cells through inhibition of NKG2D signaling pathways. Int J Oncol 49: 1704-1712, 2016.

23. Jiang G, Xin R, Yuan W, Zhang L, Meng X, Sun W, Han H, Hou Y, Wang L and Du P: Ligustrazine ameliorates acute kidney injury through downregulation of NOD2-mediated inflammation. Int J Mol Med 45: 731-742, 2020.

24. Livak KJ and Schmittgen TD: Analysis of relative gene expression data using real-time quantitative PCR and the 2(-Delta Delta C(T)) method. Methods 25: 402-408, 2001.

25. Guo M, Liu Y and Shi D: Cardiovascular actions and therapeutic potential of tetramethylpyrazine (active component isolated from rhizoma chuanxiong): Roles and mechanisms. Biomed Res Int 2016: 2430329, 2016.

26. Zheng Q, Huang YY,Zhu PC, Tong Q, Bao XY,Zhang QH,Zheng GQ and Wang Y: Ligustrazine exerts cardioprotection in animal models of myocardial ischemia/reperfusion injury: Preclinical evidence and possible mechanisms. Front Pharmacol 9: 729, 2018.

27. Mehrotra P, Sturek M, Neyra JA and Basile DP: Calcium channel Orail promotes lymphocyte IL-17 expression and progressive kidney injury. J Clin Invest 129: 4951-4961, 2019.

28. Kar F, Hacioglu C, Senturk H, Donmez DB and Kanbak G: The role of oxidative stress, renal inflammation, and apoptosis in post ischemic reperfusion injury of kidney tissue: The protective effect of dose-dependent boric acid administration. Biol Trace Elem Res 195: 150-158, 2019.

29. Chen B, Ma Y, Xue X, Wei J, Hu G and Lin Y: Tetramethylpyrazine reduces inflammation in the livers of mice fed a high fat diet. Mol Med Rep 19: 2561-2568, 2019.

30. Bai XY, Wang XF, Zhang LS, Du PC, Cao Z and Hou Y: Tetramethylpyrazine ameliorates experimental autoimmune encephalomyelitis by modulating the inflammatory response. Biochem Biophys Res Commun 503: 1968-1972, 2018.

31. Feng L, Ke N, Cheng F, Guo Y, Li S, Li Q and Li Y: The protective mechanism of ligustrazine against renal ischemia/reperfusion injury. J Surg Res 166: 298-305, 2011.

32. Qing L, Wu P, Zhou Z, Yu F and Tang J: Tetramethylpyrazine improved the survival of multiterritory perforator flaps by inducing angiogenesis and suppressing apoptosis via the Akt/Nrf2 pathway. Drug Des Devel Ther 13: 1437-1447, 2019.

33. Zhang F, Jin H, Wu L, Shao J, Wu X, Lu Y and Zheng S: Ligustrazine disrupts lipopolysaccharide-activated NLRP3 inflammasome pathway associated with inhibition of Toll-like receptor 4 in hepatocytes. Biomed Pharmacother 78: 204-209, 2016.

34. Wu X, Zhang F, Xiong X, Lu C, Lian N, Lu Y and Zheng S: Tetramethylpyrazine reduces inflammation in liver fibrosis and inhibits inflammatory cytokine expression in hepatic stellate cells by modulating NLRP3 inflammasome pathway. IUBMB Life 67: 312-321, 2015.

35. Huang X, Zuo L, Lv Y, Chen C, Yang Y, Xin H, Li Y and Qian Y: Asiatic acid attenuates myocardial ischemia/reperfusion injury via Akt/GSK-3 $\beta / \mathrm{HIF}-1 \alpha$ signaling in rat H9c2 cardiomyocytes. Molecules 21: 1248, 2016.

36. Nicholas SA, Bubnov VV, Yasinska IM and Sumbayev VV: Involvement of xanthine oxidase and hypoxia-inducible factor 1 in Toll-like receptor 7/8-mediated activation of caspase 1 and interleukin-1 $\beta$. Cell Mol Life Sci 68: 151-158, 2011. 
37. Ouyang X, Ghani A, Malik A, Wilder T, Colegio OR, Flavell RA Cronstein BN and Mehal WZ: Adenosine is required for sustained inflammasome activation via the $\mathrm{A}_{2} \mathrm{~A}$ receptor and the HIF-1 $\alpha$ pathway. Nat Commun 4: 2909-2909, 2013.

38. Cosin-Roger J, Simmen S, Melhem H, Atrott K, Frey-Wagner I, Hausmann M, de Vallière C, Spalinger MR, Spielmann $\mathrm{P}$, Wenger RH, et al: Hypoxia ameliorates intestinal inflammation through NLRP3/mTOR downregulation and autophagy activation. Nat Commun 8: 98, 2017.

39. Sokulsky LA, Goggins B, Sherwin S, Eyers F, Kaiko GE, Board PG, Keely S, Yang M and Foster PS: GSTO1-1 is an upstream suppressor of M2 macrophage skewing and HIF- $1 \alpha$-induced eosinophilic airway inflammation. Clin Exp Allergy 50: 609-624, 2020

40. Hernández A, Geng Y, Sepúlveda R, Solís N, Torres J, Arab JP Barrera F, Cabrera D, Moshage $\mathrm{H}$ and Arrese M: Chemical hypoxia induces pro-inflammatory signals in fat-laden hepatocytes and contributes to cellular crosstalk with Kupffer cells through extracellular vesicles. Biochim Biophys Acta Mol Basis Dis 1866: 165753, 2020.

41. Tang TT, Lv LL, Pan MM, Wen Y, Wang B, Li ZL, Wu M, Wang FM, Crowley SD and Liu BC: Hydroxychloroquine attenuates renal ischemia/reperfusion injury by inhibiting cathepsin mediated NLRP3 inflammasome activation. Cell Death Dis 9: $351,2018$.
42. Liang S, Xu Z, Ruan Y, Niu T, Guo W, Jiang W and Hou J: Isoquercitrin attenuates renal ischemia/reperfusion injury through antioxidation, anti-inflammation, and antiapoptosis in mice. Transplant Proc 52: 1014-1019, 2020.

43. Han F, Dou M, Wang Y, Xu C, Li Y, Ding X, Xue W, Zheng J, Tian P and Ding C: Cordycepin protects renal ischemia/reperfusion injury through regulating inflammation, apoptosis, and oxidative stress. Acta Biochim Biophys Sin (Shanghai) 52: 125-132, 2020.

44. Yang F, Wang Z, Wei X, Han H, Meng X, Zhang Y, Shi W, Li F, Xin T, Pang Q and Yi F: NLRP3 deficiency ameliorates neurovascular damage in experimental ischemic stroke. J Cereb Blood Flow Metab 34: 660-667, 2014.

This work is licensed under a Creative Commons Attribution-NonCommercial-NoDerivatives 4.0 International (CC BY-NC-ND 4.0) License. 